\section{Commentary: Liposomal bupivacaine intercostal nerve block. All that is gold does not glitter}

\author{
Abbas E. Abbas, MD, MS, FACS
}

Postoperative thoracic pain (PTP) is a frequently valid concern, with up to $50 \%$ of patients describing PTP for more than 12 months. ${ }^{1}$ Untreated, PTP may cause decreased mobility, pulmonary morbidities, and chronicity. ${ }^{2}$ This may result in longer hospital stays and higher healthcare costs.

The pathophysiology of PTP is multifactorial, although intercostal nerve stimulation is certainly the main culprit. Other contributing factors include intercostal neuroma, rib fracture, costochondritis, and psychologic influences. ${ }^{3-5}$ However, the exact mechanism of PTP is still largely unknown. ${ }^{6}$

Numerous studies have touted the benefits of thoracoscopic surgery compared with conventional thoracotomy regarding PTP-related outcomes. ${ }^{7,8}$ Remarkably, thoracoscopy has been associated with rates of chronic pain of $22 \%$ to $63 \%$, comparable to thoracotomy. ${ }^{9,10}$

Preemptive analgesia is known to reduce PTP..$^{11,12}$ Different modalities have been used, including patientcontrolled analgesia, intrapleural analgesia, cryoanalgesia, thoracic epidural block, paravertebral block, intercostal nerve blockade (INB), and others. ${ }^{13}$ Each of these has unique advantages and inherent risks. For example, opioids and epidural catheters may induce respiratory, hemodynamic, urinary, and gastrointestinal disturbances. ${ }^{10}$

INB allows faster recovery and less narcotic use. ${ }^{14}$ Local anesthetics are effective, safe, and cheap. Liposomeembedded bupivacaine (LEB) was developed to prolong the duration of action from 12 hours to approximately

\footnotetext{
From the Division of Thoracic Surgery, Department of Thoracic Medicine and Surgery, Lewis Katz School of Medicine at Temple University, Philadelphia, Pa.

Disclosures: Author has nothing to disclose with regard to commercial support.

Received for publication Jan 6, 2020; revisions received Jan 6, 2020; accepted for publication Jan 9, 2020; available ahead of print Feb 4, 2020.

Address for reprints: Abbas E. Abbas, MD, MS, FACS, Department of Thoracic Medicine and Surgery, Temple University Health System, Lewis Katz School of Medicine, 3401 N Broad St, Suite C-100, Philadelphia, PA 19035 (E-mail: abbas.abbas@temple.edu).

J Thorac Cardiovasc Surg 2021;161:1662-3 0022-5223/ $\$ 36.00$

Copyright $(9) 2020$ Published by Elsevier Inc. on behalf of The American Association for Thoracic Surgery

https://doi.org/10.1016/j.jtcvs.2020.01.030
}

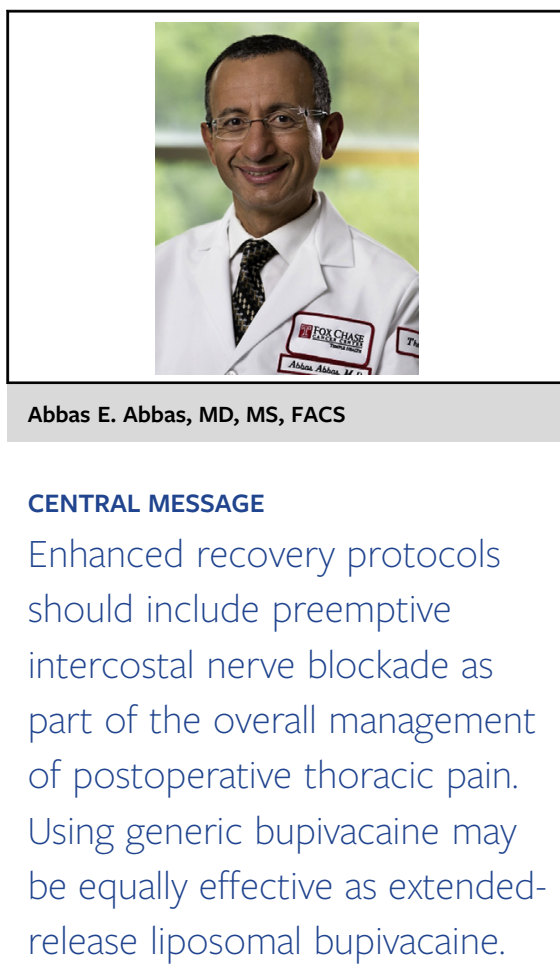

3 days. ${ }^{15}$ It is delivered through a proprietary foam-based system and costs up to 100 times the price of nonliposomal bupivacaine (NLB) $(\sim \$ 3$ per dose $) .{ }^{16}$

Weksler and colleagues ${ }^{17}$ present a randomized controlled trial (RCT) of preemptive INB for minimally invasive lung resection with LEB versus NLB. Both groups had similar postoperative opioid requirement, length of stay, and complications. The article concludes that because there was no difference in pain mitigation, the cheaper NLB should be used. The study is statistically sound, despite its shortcomings of early termination and poor accrual. However, one must ask whether this is a fair conclusion based on a negative trial of only 50 patients. Be that as it may, a second RCT comparing LEB and NLB in sternotomy was also negative, ${ }^{18}$ and it is not clear that this agent is advantageous even in other specialties.

Many issues in our field remain controversial because of a paucity of RCTs, and the investigators are commended for undertaking this study. The concept of the article is simple but useful and may serve as an impetus for surgeons to reassess their analgesic regimens. Nevertheless, one wonders why there was no benefit from this often-flaunted drug. Is it that after the initial few hours the benefit of an extendedrelease anesthetic is less important? Is it that the drug 
may not always have the longer duration effect that is advertised? Is it that thoracoscopic surgery decreases pain in such a way that LEB is less effective? Or is it that the advantages of LEB are not clinically important?

Of course, one must remember that intercostal nociception likely represents only a fraction of the entire perioperative noxious experience. It is more effective to develop comprehensive enhanced recovery protocols and clinical care pathways that include perioperative education and preemptive analgesia to truly improve clinical outcomes and cut costs.

Finally, it is not always the newer, more expensive medicine that offers the best salve for an affliction. When tempted to overlook a tried and true drug simply because it is old and cheap, one may wish to remember the whimsical words of J.R.R. Tolkien.

"All that is gold does not glitter,

Not all those who wander are lost;

The old that is strong does not wither,

Deep roots are not reached by the frost." 19

\section{References}

1. Dajczman E, Gordon A, Kreisman H, Wolkove N. Long-term postthoracotomy pain. Chest. 1991;99:270-4

2. Katz J, Jackson M, Kavanagh BP, Sandler AN. Acute pain after thoracic surgery predicts long-term post-thoracotomy pain. Clin J Pain. 1996;12:50-5.

3. Landreneau RJ, Mack MJ, Hazelrigg SR, Naunheim K, Dowling RD, Ritter P, et al. Prevalence of chronic pain after pulmonary resection by thoracotomy or video-assisted thoracic surgery. J Thorac Cardiovasc Surg. 1994;107:1079-86.

4. Landreneau RJ, Wiechmann RJ, Hazelrigg SR, Mack MJ, Keenan RJ, Ferson PF. Effect of minimally invasive thoracic surgical approaches on acute and chronic postoperative pain. Chest Surg Clin N Am. 1998;8:891-906.
5. Richardson J, Sabanathan S. Pain management in video assisted thoracic surgery: evaluation of localised partial rib resection. A new technique. J Cardiovasc Surg (Torino). 1995;36:505-9.

6. Rogers ML, Duffy JP. Surgical aspects of chronic post-thoracotomy pain. Eur J Cardiothorac Surg. 2000;18:711-6.

7. Villamizar NR, Darrabie MD, Burfeind WR, Petersen RP, Onaitis MW, Toloza E, et al. Thoracoscopic lobectomy is associated with lower morbidity compared with thoracotomy. J Thorac Cardiovasc Surg. 2009; 138:419-25

8. Ye B, Wang M. Video-assisted thoracoscopic surgery versus thoracotomy for non-small cell lung cancer: a meta-analysis. Comb Chem High Throughput Screen. 2019;22:187-93.

9. Bayman EO, Parekh KR, Keech J, Selte A, Brennan TJ. A prospective study of chronic pain after thoracic surgery. Anesthesiology. 2017;126:938-51.

10. Gottschalk A, Cohen SP, Yang S, Ochroch EA. Preventing and treating pain after thoracic surgery. Anesthesiology. 2006;104:594-600.

11. Katz J, Kavanagh BP, Sandler AN, Nierenberg H, Boylan JF, Friedlander M, et al Preemptive analgesia. Clinical evidence of neuroplasticity contributing to postoperative pain. Anesthesiology. 1992;77:439-46.

12. Doyle E, Bowler GM. Pre-emptive effect of multimodal analgesia in thoracic surgery. Br J Anaesth. 1998;80:147-51.

13. Gerner P. Postthoracotomy pain management problems. Anesthesiol Clin. 2008 26:355-67.

14. Benedetti F, Vighetti S, Ricco C, Amanzio M, Bergamasco L, Casadio C, et al Neurophysiologic assessment of nerve impairment in posterolateral and muscle-sparing thoracotomy. J Thorac Cardiovasc Surg. 1998;115:841-7.

15. Gadsden J, Long WJ. Time to analgesia onset and pharmacokinetics after separate and combined administration of liposome bupivacaine and bupivacaine $\mathrm{HCl}$ considerations for clinicians. Open Orthop J. 2016;10:94-104.

16. Kim K, Elbuluk A, Yu S, Iorio R. Cost-effective peri-operative pain management assuring a happy patient after total knee arthroplasty. Bone Jt J. 2018;100-B(1 Supple A):55-61.

17. Weksler B, Sullivan JL, Schumacher LY. Randomized trial of bupivacaine with epinephrine versus bupivacaine liposome suspension in patients undergoing minimally invasive lung resection. J Thorac Cardiovasc Surg. 2021;161:1652-61.

18. Lee CY, Robinson DA, Johnson CA, Zhang Y, Wong J, Joshi DJ, et al. A randomized controlled trial of liposomal bupivacaine parasternal intercostal block for sternotomy. Ann Thorac Surg. 2019;107:128-34.

19. Tolkien JRR. The Fellowship of the Ring. New York: Ballantine Books; 1982. 